\title{
High-quality and deeply excavated PtPdNi nanocubes as efficient catalysts toward oxygen reduction reaction
}

\author{
Yanjie Li, Rifeng Wu, Yang Liu, Ying Wen, Pei Kang Shen* \\ Collaborative Innovation Center of Sustainable Energy Materials, Guangxi Key Laboratory of Electrochemical Energy Materials, State Key Laboratory of \\ Processing for Non-ferrous Metal and Featured Materials, Guangxi University, Nanning 530004, Guangxi, China
}

\section{A R T I C L E I N F O}

\section{Article history:}

Received 18 April 2020

Accepted 23 June 2020

Available online 22 September 2020

\section{Keywords:}

Oxygen reduction reaction

Polymer electrolyte fuel cells

Concave cubic structure

Electrochemical catalyst

\begin{abstract}
A B S T R A C T
The oxygen reduction reaction (ORR) on the cathode of a polymer electrolyte fuel cell requires the use of a catalyst based on Pt, one of the most expensive metals on the earth. A number of strategies, including optimization of a different metal into the core, have been investigated to enhance the activity of a Pt-based catalyst and thus reduce the loading of Pt. By dedicating to compounding high catalytic activity $\mathrm{Pt}_{2.7} \mathrm{Pd}_{0.3} \mathrm{Ni}$ concave cubic with high index crystal face, the paper shows that concave structures can offer more active site and high level of catalytic activity and if mixed with other metal, decrease the proportion of Pt and improve its mass activity. The paper also makes an exploration into the theory and conditions behind the formation of $\mathrm{Pt}_{2.7} \mathrm{Pd}_{0.3} \mathrm{Ni}$ concave cubic structure, and investigates the difference it demonstrates by modifying the reactive conditions. The results of the oxygen reduction performance of the electrochemical test are as follows: the concave cube-shaped Pt-Pd-Ni catalyst has a mass activity of $1.28 \mathrm{~A} \mathrm{mg}_{\mathrm{Pt}^{-1}}$ at $0.9 \mathrm{~V}$, its highest mass activity is 8.20 times that of commercial Pt/C, and its specific activity is 8.68 times of that commercial Pt/C. And the Pt-Pd-Ni ternary nanocage has excellent structural invariance. After the stability test, there is no obvious structural change and performance degradation in the nanostructure.
\end{abstract}

(C) 2021, Dalian Institute of Chemical Physics, Chinese Academy of Sciences. Published by Elsevier B.V. All rights reserved.

\section{Introduction}

As the most effective single metal catalyst, platinum (Pt) is widely used in proton exchange membrane fuel cells (PEMFCs) [1]. Metal Pt has been facing problems such as resource shortage and high price. In addition, there are still many unsolved problems, like slow kinetics of cathodic oxidation-reduction reaction and low catalytic activity, which limit the widespread commercialization of the PEMFCs cars [2]. Therefore, increasing the utilization of $\mathrm{Pt}$, intrinsic catalytic activity and stability are the research priorities. The catalytic activity, stability and anti-toxicity of nanocrystals mainly depend on factors such as size, morphology, composition and surface state [3-6]. There are two main considerations for reducing production costs. One is to increase the active mass of the prepared catalyst, and the other is to reduce the amount of precious metal at the same active mass. And one of the most commonly used strategies is to precisely control the structure of Pt nanocrystals [6-9]. The size, morphology, surface and structure of noble metal nanomaterials largely determine the properties of noble metal nanomaterials. The prepared hollow, porous, concave or transparent geometric shape can effectively reduce the amount of $\mathrm{Pt}$ metal and lower the cost, and the surface structure of some alloys with special morphology can enhance the activity of the

\footnotetext{
* Corresponding author. Tel: +86-771-3237990; E-mail: pkshen@gxu.edu.cn

This work was supported by the link project of the National Natural Science Foundation of China and Fujian Province (U1705252), the Guangxi Science and Technology Project (AA17204083, AB16380030), and the Natural Science Foundation of Guangdong Province (2015A030312007). DOI: 10.1016/S1872-2067(20)63703-2 | http://www.sciencedirect.com/science/journal/18722067 | Chin. J. Catal., Vol. 42, No. 5, May 2021
} 
catalyst. Accordingly, the synthesis of nano-alloy catalysts with controllable morphology is a prerequisite for the development of the catalytic activity. Another strategy for improving the catalytic performance of platinum is to modulate the composition of Pt nanocrystals, such as forming platinum-based alloys by introducing transition metals have significantly enhanced catalytic performance. Researches show that the atomic utilization of Pt can be significantly increased by regulating the composition of Pt nanocrystals. On the other hand, multicomponent alloys can increase the intrinsic activity of platinum by electronic effects, ligand effects or synergistic effects [10-14]. In recent years, ternary alloys have gained much attention because they are more controllable for regulation and are expected to further improve the catalytic performance of platinum. A growing number of people have been interested in nanocrystals with high-index crystal planes. The high-index crystal contains high-density step atoms and kink atoms. Because of its low coordination number, it is easy to interact with reactive molecules and become a catalytically active center. And its catalytic activity and stability are significantly better than that of the low-index crystal [15-18]. However, the higher surface energy of high-index crystals poses a great challenge to protect the high-index crystal during crystal growth. At present, single-phase noble metal catalysts with high-index crystal have been synthesized, including Pt, PtPd, PtNi, PtCo, and PtCu alloys [19-24]. Specific synthesis methods include square wave potential method, hydrothermal method, and liquid phase reduction method. But the growth mechanism of high-index crystals is unclear and this requires a lot of practice. In conclusion, it is of great research significance to prepare concave cube-shaped Pt-Pd-Ni catalyst and achieve composition regulation.

As early as 2007, Stamenkovic et al. [24] reported the use of $\mathrm{Pt}_{3} \mathrm{Ni}$ (111) as a high-performance catalyst. The surface of $\mathrm{Pt}_{3} \mathrm{Ni}$ (111) is rich in Pt and the subsurface is rich in Ni. This structure reduces the $d$-band center by $0.34 \mathrm{eV}$, which weaken the adsorption of oxygen-containing substances by Pt atoms on the surface, thereby revealing more active sites for further oxygen adsorption and reactions. Experimental results show that the activity of $\mathrm{Pt}_{3} \mathrm{Ni}$ (111) is 10 times higher than that of Pt (111), which is 90 times higher than that of commercial Pt-C catalyst [25]. Then, Fang et al. [25] reported the preparation of octahedral PtNi nanocrystals and Wu et al. [26] reported the preparation of octahedral, truncated octahedral, and cubic shapes PtNi. The Pt-rich Pt-Ni concave cube structure synthesized by hydrothermal method was prepared by Zhang's research group with PVP in 2017 [28]. In this paper, a one-step method is used to synthesize a concave cube-shaped PtPdNi catalyst with high-index crystal planes with high catalytic activity. Compared with the cubic structure, the high index crystal plane of the concave cube structure can provide more active sites and stronger catalytic activity, while the PtNi cube has stronger catalytic activity and stability than that of the Pt cube. And doping Pd in PtNi cube will slow down the autocatalysis of Pt and lead to a slow homogeneous reaction in solution, and the Pt atoms enriched on the vertices of the cube will be covered by $\mathrm{Br}$ - and mainly diffuse along $<111>$ to final form as a concave cube structure. In this paper, the formation mechanism and formation conditions of concave cube-shaped PtPdNi catalyst are also studied. Concave cubes of different element types can be formed by controlling the precursor and the reaction temperature; the degree of unevenness (degree) of the concave cube can be changed by controlling the amount of the reducing agent and the reaction time. And they are physically characterized in this paper. In the laboratory-made closed three-electrode system, a series of electrochemical tests such as oxygen reduction performance and stability are performed on the concave cubic catalyst. The analysis shows that the concave cubic catalyst has better electrocatalytic performance.

\section{Experimental}

\subsection{Preparation method of concave cube-shaped Pt Pt-Ni and Pt-Pd-Ni catalyst with high-index crystal planes}

Transfer $7 \mathrm{~mL}$ of oleylamine solution and $3 \mathrm{~mL}$ of DMF solution to a $25 \mathrm{~mL}$ PTFE liner. Dissolve $0.63 \mathrm{~mL}$ of a $\mathrm{H}_{2} \mathrm{PtCl}_{6}$ solution with a concentration of $15.78 \mathrm{mgPt}_{\mathrm{PL}}^{-1}$ and $0.35 \mathrm{~mL}$ of a $20 \%$ methylamine water solution into the solution successively or dissolve $350 \mathrm{mg} \mathrm{CTAB}, 17 \mathrm{mg} \mathrm{Ni(acac)} 2$ and transfer $0.63 \mathrm{~mL}$ of a $\mathrm{H}_{2} \mathrm{PtCl}_{6}$ solution with a concentration of $15.78 \mathrm{mgt}_{\mathrm{Pt}} \mathrm{mL}^{-1}$ into the solution successively or dissolve $350 \mathrm{mg} \mathrm{CTAB}$ and 17 mg Ni(acac) 2, and transfer $0.63 \mathrm{~mL}$ of a $\mathrm{H}_{2} \mathrm{PtCl}_{6}$ solution with a concentration of $15.78 \mathrm{mgPt}_{\mathrm{mL}}^{-1}$ and $0.63 \mathrm{~mL}$ of a $\mathrm{H}_{2} \mathrm{PdCl}_{4}$ Solution with a concentration of $15.78 \mathrm{mg}_{\mathrm{Pt}} \mathrm{mL}^{-1}$ into the solution successively. The mixed solution in the liner is stirred at room temperature for $10 \mathrm{~min}$ and then sealed with a stainless steel reaction kettle. The stainless steel reaction kettle is moved into an oil bath pan maintained at $160{ }^{\circ} \mathrm{C}$, and the reaction was incubated for $24 \mathrm{~h}$ with the aid of magnetic stirring. After the reaction, a certain amount of $n$-butylamine is added, and the mixture was ultrasonically washed and centrifuged at 9000 rpm for $15 \mathrm{~min}$. Then the mixture is washed with a mixture of absolute ethyl alcohol and deionized water and centrifuged twice. And the final sample is dispersed in the absolute ethyl alcohol.

\subsection{Preparation method of Pt-Pd-Ni alloy hyperbranched nanostructures}

Transfer $9 \mathrm{~mL}$ of oleylamine solution and $1 \mathrm{~mL}$ of DMF solution to a $25 \mathrm{~mL}$ PTFE liner. Dissolve $350 \mathrm{mg}$ CTAB and $17 \mathrm{mg}$ $\mathrm{Ni}$ (acac) 2, and transfer $0.63 \mathrm{~mL}$ of a $\mathrm{H}_{2} \mathrm{PtCl}_{6}$ solution with a concentration of $15.78 \mathrm{mgt}_{\mathrm{Pt}}^{-1}$ and $0.63 \mathrm{~mL}$ of a $\mathrm{H}_{2} \mathrm{PdCl}_{4} \mathrm{So}$ lution with a concentration of $15.78 \mathrm{mgPt}_{\mathrm{Pt}} \mathrm{mL}^{-1}$ into the solution successively. The mixed solution in the liner is stirred at room temperature for $10 \mathrm{~min}$ and then sealed with a stainless steel reaction kettle. The stainless steel reaction kettle is moved into an oil bath pan maintained at $160{ }^{\circ} \mathrm{C}$, and the reaction was incubated for $24 \mathrm{~h}$ with the aid of magnetic stirring. After the reaction, a certain amount of $n$-butylamine is added, and the mixture was ultrasonically washed and centrifuged at 9000 rpm for $15 \mathrm{~min}$. Then the mixture is washed with a mixture of absolute ethyl alcohol and deionized water and centrifuged 
twice. And the final sample is dispersed in the absolute ethyl alcohol.

\subsection{Preparation and activation of carbon supported nanocube catalysts}

The prepared catalyst was loaded onto a proper amount of carbon powder (Cabot, Vulcan XC-72), and the mass fraction of Pt in the catalyst was $17 \%-20 \%$. The long chain surfactants and oleamine molecules on the catalyst surface were dissolved with chloroform, and the dispersion process was completed by ultrasonic treatment for 30 to $45 \mathrm{~min}$. The catalyst powder was collected by centrifugation (10000 rpm) and washed with hexane, then centrifuged to remove chloroform. The obtained catalyst powder was heated in air at $200{ }^{\circ} \mathrm{C}$ for $24 \mathrm{~h}$ to remove organic surfactant and make it fully combined with carbon powder.

\subsection{Preparation and electrochemical characterization of electrode}

The catalyst was mixed with $0.02 \mathrm{~mL} 0.5 \%$ Nafion solution and $0.18 \mathrm{~mL}$ ethanol solution to form catalyst ink with concentration of $0.5 \mathrm{mg} / \mathrm{mL}$. The actual concentration of $\mathrm{Pt}$ in the ink was determined by ICP-AES. The catalyst ink is dropped onto the cleaned glassy carbon electrode with a radius of $5 \mathrm{~mm}$ (geometric area of $0.196 \mathrm{~cm}^{-2}$ ) at a proper speed, and dried as the working electrode. Take $2 \mathrm{mg}$ of commercial Pt/C catalyst (TKK, $44.7 \% \mathrm{Pt}$ ) and prepare the $\mathrm{Pt} / \mathrm{C}$ ink according to the same steps. The loading mass of commercial Pt/C catalyst is 7.8 $\mu \mathrm{g}_{\mathrm{Pt}} \mathrm{cm}^{-2}$ by ICP-AES. The electrochemical measurement was carried out by using the rotating disk electrode (RDE) and biological VSP electrochemical workstation. Using reversible hydrogen electrode as reference electrode and Pt foil as counter electrode, and using $0.1 \mathrm{M} \mathrm{HClO}_{4}$ prepared from $67 \% \mathrm{HClO}_{4}$ as electrolyte. All potentials were compared with reversible hydrogen electrode (RHE). The range of cyclic voltammetry (CV) is $0.05-1.02 \mathrm{~V}$. Before cyclic voltammetry, the electrolyte saturated with $\mathrm{N}_{2}$ or Ar to remove the adsorbate, and cyclic voltammetric curve was obtained with a scanning rate of $50 \mathrm{mV} / \mathrm{s}$. The linear sweep voltammetry (LSV) was collected with a scanning rate of $5 \mathrm{mV} / \mathrm{s}$ when the rotating disk electrode was rotating at $1600 \mathrm{rpm}$ in the $\mathrm{O}_{2}$-saturated electrolyte. The accelerated aging experiment was carried out at a scanning rate of $100 \mathrm{mV} / \mathrm{s}$ with the range of $0.6-1.1 \mathrm{~V}$ in a $\mathrm{O}_{2}$-saturated electrolyte. The LSV curve was continuously carried out for 10000 cycles. The linear sweep voltammetric curves have been ohmic corrected. The test temperature is constant at $25^{\circ} \mathrm{C}$.

\section{Results and discussion}

The concave cube-shaped Pt-Pd-Ni catalyst can be directly prepared in one step by a simple stirring assisted solvothermal method. In the experiment, $\mathrm{H}_{2} \mathrm{PtCl}_{6}$ solution, $\mathrm{H}_{2} \mathrm{PdCl}_{4}$ solution, $\mathrm{Ni}$ (acac) $)_{2}$ were dissolved and reduced with a mixed solution of oleylamine and $\mathrm{N}, \mathrm{N}$-dimethylformamide in the presence of cetyl trimethyl ammonium bromide (CTAB), wherein CTAB is used as surfactant and structural guide.

In the first part, we have fully characterized and analyzed the synthesized products by transmission electron microscopy. Figs. 1(a) and (b) are low-magnification TEM image and STEM image of the product. It can be seen from the images that the nanoparticles are uniformly distributed and the morphology is basically cubic, with the yield approaching $100 \%$. As shown in Fig. 1, the final products were then collected and characterized in detail. A representative transmission electron microscopy (TEM) image demonstrates that the nanocrystals are high-quality cubic structure with uniform size and morphology (Fig. 1(a)). The average edge length of the nanocubes is 33.2 $\mathrm{nm}$. According to the high angle annular dark field scanning transmission electron microscopy (HAADF-STEM) image of the as-obtained products (Fig. 1(b)), the square diagonals are much brighter than other parts of the nanocrystals, which looks like an $\mathrm{X}$ in a square, and the brightness of the diagonals shows a linear trend to reduce from the vertex angle to the center of the square. This indicates that the surfaces of nanocubes were deeply excavated. TEM images of individual nanocrystal were recorded along different zone axes, and a series of TEM images at different rotations of selected nanocrystals were obtained (Figs. 1(c1), (c2), (c3)). It can match well with the TEM figures, which indicates that the six faces of the nanocubes were all deeply excavated. Moreover, our detailed analysis shows that the angle between nanosheet and surface of the ideal nanocube is about $45^{\circ}$, and the nanosheets face-to-face form isosceles trapez (Fig. 1(c1)). These analyses strongly confirm that the

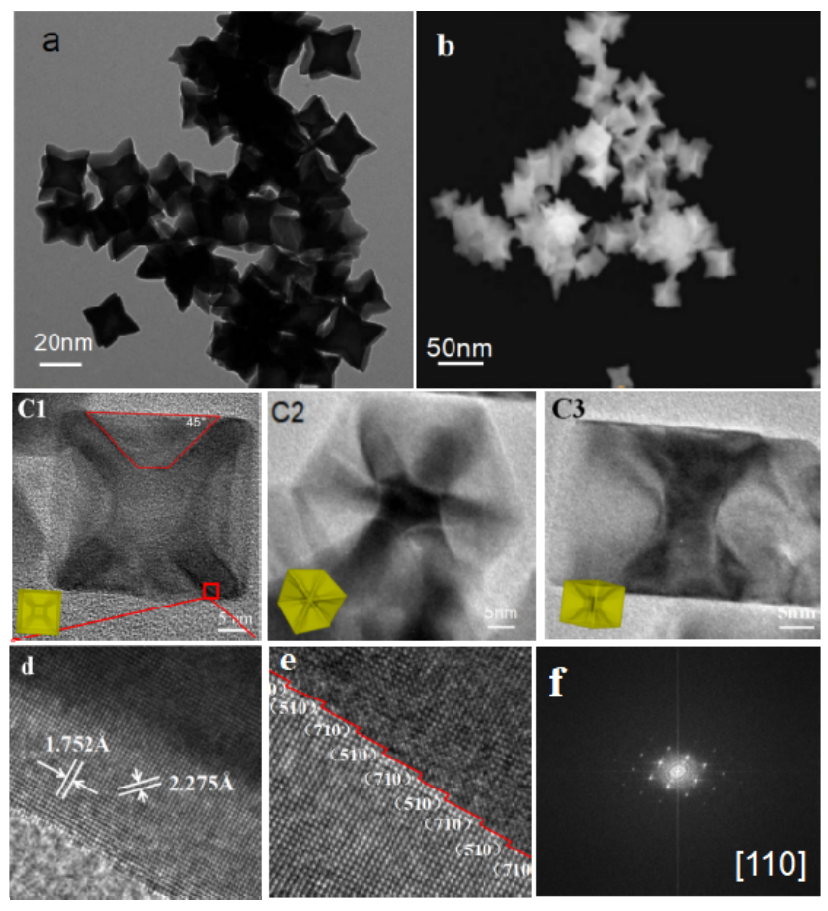

Fig. 1. TEM (a) and HAADF-STEM (b) images of $\mathrm{Pt}_{2.7} \mathrm{Pd}_{0.3} \mathrm{Ni}$ DENCs; (c1, c2, c3) TEM images and schematic models of individual $\mathrm{Pt}_{2.7} \mathrm{Pd}_{0.3} \mathrm{Ni}$ DENCs; (d) HRTEM image taken from the red region boxed in (c1); (e) Enlarged HRTEM image taken from the edge of an individual $\mathrm{Pt}_{2.7} \mathrm{Pd}_{0.3} \mathrm{Ni}$ DENC and illustration of the atomic arrangement; (f) Corresponding fast Fourier transform (FFT) pattern of the $\mathrm{Pt}_{2.7} \mathrm{Pd}_{0.3} \mathrm{Ni}$ DENC shown in (c1). 
nanocubes were deeply excavated. And the nanostructure of a deeply excavated nanocube can be regarded as an assembly of 12 isosceles right triangle nanosheets side by side. HRTEM and the corresponding fast Fourier transform (FFT) pattern were obtained from [110] zone axis and other orientations (Fig. 1(f)), which indicate high crystallinity of the nanocrystals. Simultaneously, the interplanar spacing of the nanocrystals (2.275 and $1.752 \AA$ ) is slightly larger than that of the pure Pt (1.96 and 1.39 $\AA$ ), which means that the Ni was successfully introduced into the Pt lattice. The atomic-resolution TEM image (Fig. 1(e)) recorded from the nanocube edge shows an atomic step composed of (510) and (710), which reveals that the edges of the nanoparticles are incurved and the 12 edges expose high-index facets [29].

To investigate the composition and element distribution of as-prepared deeply excavated nanocubes, both energy dispersive X-ray (EDX) spectroscopy elemental mapping and line scanning were performed. The elemental mapping images (Fig. 2(a)) clearly indicate that the Pt, Pd and Ni are uniformly distributed in the whole nanocube, which is further confirmed by the line-scanning profile recorded across individual deeply excavated nanocubes along the red path (Fig. 2(b)). The EDX spectroscopy analysis (Fig. 2(c)) shows that the atomic ratio of $\mathrm{Pt}, \mathrm{Pd}$ and $\mathrm{Ni}$ is 61:6:33 (approximately equal to 2.7:0.3:1), which can match pretty well with the result of inductively coupled plasma atomic emission spectroscopy (ICP-AES). The X-ray diffraction (XRD) pattern (Fig. 2(d)) of the nanocubes shifted to the higher degree compared with the fcc Pt, Pd, Ni PDF standard card, which confirms a face-centered-cubic (fcc) structure [30].

\subsection{Study on the formation mechanism of concave cube-shaped PtPdNi catalysts}

It has shown that PtPd can be uniformly distributed in the presence of $\mathrm{Br}^{-}$when $\mathrm{OAM}$ is used as solvent and reducing agent. And the presence of $\mathrm{Br}^{-}$promotes the nanocrystals to form cubes, that is, $\mathrm{Pt}$ atoms are selectively deposited and grown at the corners of the cubes, there by forming cubic nanocrystals in which Pt and Pd are uniformly distributed. In addition, DMF solutions are commonly used to prepare polyhedral Pt-Ni alloy nanocrystals. Studies have shown that platinum and nickel in cubic Pt-Ni alloy nanocrystals prepared by using DMF solution as solvent and reducing agent are also relatively separated, in which Pt elements are mainly distributed on the ribs, while Ni atoms are mainly distributed on the (110) plane of the cube [31-34]. Therefore, we used $\mathrm{H}_{2} \mathrm{PtCl}_{6} \cdot 6 \mathrm{H}_{2} \mathrm{O}$, $\mathrm{H}_{2} \mathrm{PdCl}_{4}$ and $\mathrm{Ni}(\mathrm{acac})_{2}$ as precursors, and CTAB as a surface reducing agent to prepare concave cube-shaped PtNi catalyst. They are dissolved together in a mixed solution of OAM and DMF, and a concave cube with three elements of Pt-Pd-Ni uniformly distributed was obtained by a one-pot method. Considering that the redox potentials of $\mathrm{Pt}, \mathrm{Pd}$ and $\mathrm{Ni}$ ions are different in the presence of $\mathrm{Br}^{-}$, among which $\mathrm{PtBr}_{6}{ }^{2-} / \mathrm{Pt}(0.59 \mathrm{~V}$ vs $\mathrm{RHE})$ and $\mathrm{PdBr}_{6}{ }^{2-} / \mathrm{Pd}(0.6 \mathrm{~V}$ vs RHE) are relatively close and much larger than $\mathrm{Ni}^{2+} / \mathrm{Ni}(-0.25 \mathrm{~V}$ vs RHE), the growth of nanocrystals is mainly divided into two stages: firstly, the cubic nanocrystals with uniform distribution of Pt-Pd are obtained; secondly, new Pt, Pd and $\mathrm{Ni}$ atoms are deposited at the corners of the cube nanocrystals, and then diffusion and anisotropic growth occur $[14,35]$. With the reaction time increases, Pt and
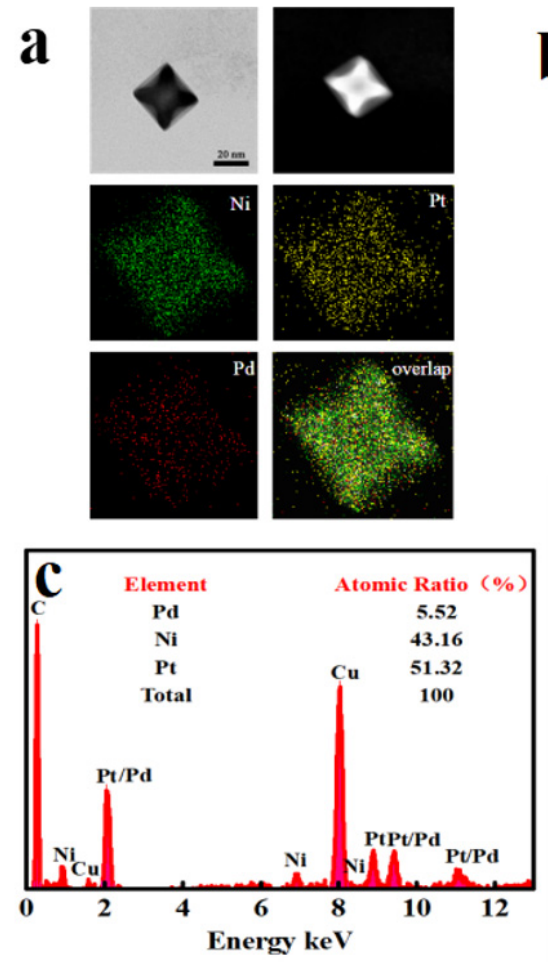
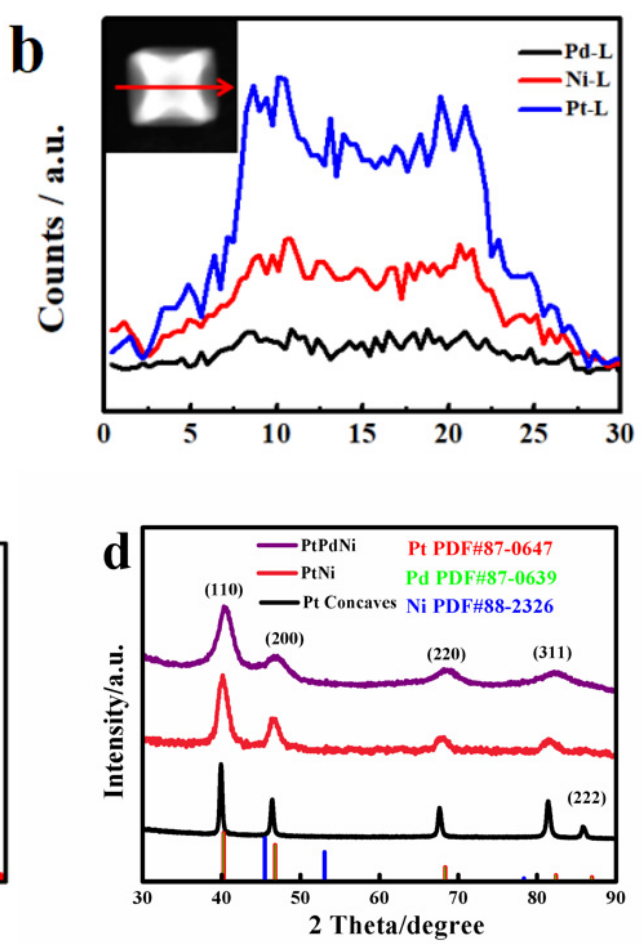

Fig. 2. (a) HAADF-STEM images and corresponding EDX mapping images of individual Pt-Pd-Ni DENC; (b) Line-scanning profiles for Pt, Pd and Ni recorded across the red line shown in the inset; EDX spectrum (c) and XRD patterns (d) of the Pt-Pd-Ni DENCs. 
Pd diffuse to the entire concave cube and are evenly distributed. In particular, the addition of a halogen ion-containing surfactant causes the nanocrystals to be affected by oxidative corrosion during the reaction, which corrodes the surface Ni atoms. And, surfactants tend to have a certain selective adsorption capacity, which will affect the deposition, diffusion and growth process of atoms. Moreover, Pt-Pd-Ni has a higher catalytic activity than Pt-Ni, because the mixture of $\mathrm{Pd}$ atoms has changed the electronic structure of $\mathrm{Pt}$, and the $d$-orbital electron number of Pt atom in binary Pt-Pd alloy system is less than that of pure $\mathrm{Pt}$, which will cause the flow of electrons from metal atoms to adsorbate $\left.\mathrm{O}_{2}\right)$ in the oxygen reduction process. In the meantime, the $d$ holes of Pt atoms increases, and the electrons of PtPd alloy flow to $\mathrm{O}_{2}$ antibond $\pi^{*}$ orbit, which will finally cause more oxygen adsorption and $0-0$ bond weakening, as well as the accelerated bond rupture between oxygen molecules and hence enhances the catalytic activity. Therefore, we use CTAB as a surface reducing agent, a mixed solution of $\mathrm{OAM}$ and DMF as a solvent and a reducing agent, and a one-pot method is used to obtain a concave cube in which three elements of Pt-Pd-Ni are evenly distributed.

In synthetic formulations, CTAB plays a key role in the preparation of concave cubes. Without the addition of CTAB during the synthesis, the product will be a solid polyhedral nanocrystal. After acid treatment, these solid nanoparticles will become hollow structures, which indicates that Ni-rich Pt-Ni polyhedral nanocrystals in the core can be prepared without adding CTAB. In CTAB molecules, bromine ions are functional groups that control the concave cube structure, it can selec- tively adsorb on the $\{100\}$ surface of the metal and combine with oxygen to form an oxidizing etchant $\left(\mathrm{Br}^{-} / \mathrm{O}_{2}\right)[6,35]$. In addition, the reason why $\mathrm{CTA}^{+}$contributes to the dispersibility of the nanocrystals and the formation of the step surface may lie in the longer amine chain of $\mathrm{CTA}^{+}$, which is similar in size to the atomic spacing of high-index crystal planes [21,36]. The following are different ratios of DMF to oleylamine mixtures as reducing agents. We have found that oleylamine as a weaker reducing agent than DMF can slow down the deposition rate of $\mathrm{PtNi}$ and reduce the deposition rate ratio of $\mathrm{Pt} / \mathrm{Ni}$, resulting in more Pt atoms enriched at the apex migration along <111> rather than along the $<100>$ direction. As the reaction time prolongs, more and more Pt atoms migrate to the (111) plane and stack, resulting in the formation of a concave cubic structure (Fig. 3(d)), and Pt atoms enriched at the apex migration along $<111>$ resulting in the formation of a Pt-Pd-Ni alloy hyperbranched nanostructure (Fig. 3(c)). And the higher the proportion of DMF, the smaller the concave surface is (Fig. 2).

The figure below shows the formation of a nano-frame of concave cube-shaped PtPdNi. At the nucleation stage, the single crystal cube surrounded by (111) and (100) planes represents thermodynamically the most stable shape, especially in the presence of corrosion, because this polyhedron is a typical Woolf polyhedron with the lowest surface energy. At the growth stage, considering the selective adsorption of $\mathrm{Br}^{-}$on the $\{100\}$ plane, and the rapid reduction of platinum and palladium, the deposition rate of atoms at the corners of the seed crystal will be greater than the rate of diffusion along the $<110>$ direction and along the $<100>$ direction, leading to the

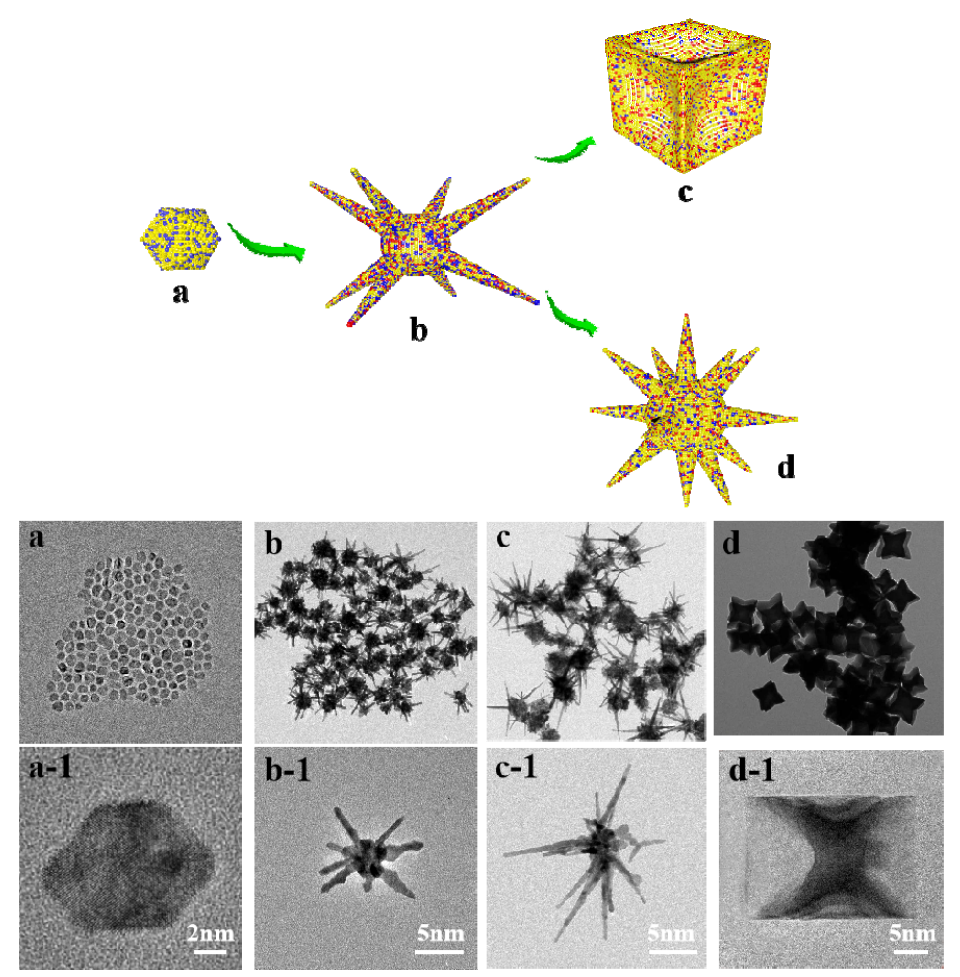

Fig. 3. TEM images of the gold products obtained after a reaction time of $5 \mathrm{~min}(\mathrm{a}, \mathrm{a}-1), 60 \mathrm{~min}(\mathrm{~b}, \mathrm{~b}-1)$, and TEM images of the Pt-Pd-Ni with different morphology controlled by tuning the feeding amounts of DMF and OAM (c,c-1) $1 \mathrm{~mL}$ DMF and $9 \mathrm{~mL}$ OAM resulting in the formation of Pt-Pd-Ni alloy hyperbranched nanostructures, $(\mathrm{d}, \mathrm{d}-1) 3 \mathrm{~mL}$ DMF and $7 \mathrm{~mL}$ OAM resulting in the formation of concave cubic structure. 
concave cube where the crystal nucleus grows selectively. Then, as the concentration of the platinum precursor in the reaction system decreases, the slow deposition of newly generated atoms at the corners and growth along the $<111>$ direction will dominate. Corrosion of halogen element $/ \mathrm{O}_{2}$ is very important for forming concave cubes. If halogen ions are avoided and oxygen is removed (the reaction solution is heated before the reaction is carried out in a sealed hydrothermal kettle), oxidative corrosion will be effectively removed and the final product will be solid nanoparticles.

\subsection{Performance of the oxygen reduction catalysis}

The concave cubic-shaped nanostructure of the prepared Pt-Pd-Ni ternary alloy is loaded onto commercial carbon powder (Cabot, Vulcant-72), long-chain surfactants and oleylamine molecules are replaced by $\mathrm{C}_{4} \mathrm{H}_{11} \mathrm{~N}$, and then the catalyst powder is heat-treated in air at $200{ }^{\circ} \mathrm{C}$ for $1 \mathrm{~h}$ to finally obtain the carbon-supported concave cubic-shaped Pt-Pd-Ni catalyst. Since Pt-Ni and Pt-Pd binary alloy nanocrystals generally exhibit enhanced oxygen reduction activity, we investigate the catalytic performance of concave cube-shaped Pt catalyst, concave cube-shaped P-tNi catalyst, and concave cube-shaped Pt-Pd-Ni catalyst in oxygen reduction reactions.

We take commercial Pt/C from Tanaka Kikinzoku (TKK, Japan) as a standard catalyst. The CV curves for concave cube-shaped Pt catalyst, concave cube-shaped PtNi catalyst, and concave cube-shaped Pt-Pd-Ni catalyst and commercial Pt/C were recorded in a $\mathrm{N}_{2}$ saturated $0.1 \mathrm{M} \mathrm{HClO}_{4}$ electrolyte. Based on the amount of electric quantity in the hydrogen desorption region (0.05-0.40 V) in the CV curve, we are able to obtain electrochemically active areas (ECSAs) of these catalysts. The results show that the ECSAs of concave cube-shaped Pt catalyst, concave cube-shaped PtNi catalyst, and concave cube-shaped
Pt-Pd-Ni catalyst are 37.9, 39.4 and $44.7 \mathrm{~m}^{2} \mathrm{gPt}^{-1}$, respectively, which is similar to the ECSAs results. The ECSAs of $\mathrm{Pt}_{3} \mathrm{Ni}$ nanomaterials is $44.2 \mathrm{~m}^{2} \mathrm{gPt}^{-1}$ and the ECSAs of Pt octahedron nanocage is $38.2 \mathrm{~m}^{2} \mathrm{gPt}^{-1}$, indicating that $\mathrm{Pt}-\mathrm{Pd}-\mathrm{Ni}$ have a high atomic utilization.

The Fig. 4 shows the oxygen reduction LSV curve measured at a sweep rate of $10 \mathrm{mV} / \mathrm{s}$ of concave cube-shaped Pt catalyst, concave cube-shaped PtNi catalyst, and concave cube-shaped $\mathrm{Pt}$-Pd-Ni catalyst in an $\mathrm{O}_{2}$-saturated $0.1 \mathrm{M} \mathrm{HClO}_{4}$ electrolyte. Their electrocatalytic activity in the oxygen reduction reaction is obviously better than that of commercial Pt/C, in which their half-wave potential are positively shifted 32, 49 and $57 \mathrm{mV}$ than that of commercial Pt/C (Fig. 4(b)). The mass activities of the concave cube-shaped Pt catalyst, concave cube-shaped PtNi catalyst, and concave cube-shaped Pt-Pd-Ni catalyst are 0.468, 1.051, and 1.279 $\mathrm{A} \mathrm{mg}_{\mathrm{Pt}^{-1}}$, respectively, which are 3.02, 6.74, and 8.21 times higher than that of commercial Pt/C (Fig. 4(c)). The specific activities of the concave cube-shaped Pt catalyst, concave cube-shaped PtNi catalyst, and concave cube-shaped PtPdNi catalyst are 1.288, 1.546, and $1.864 \mathrm{~A} \mathrm{~cm}^{-2}$, which are 6.02, 7.21, and 8.68 times higher than that of commercial Pt/C (Fig. 4(d)). And the increase in catalyst activity is mainly due to the higher atomic utilization (structure) and the synergistic effect (composition) between the metals. The ternary alloy formed after the introduction of $\mathrm{Ni}$ atoms can change the electronic structure of $\mathrm{Pt}$ and weaken the adsorption capacity of $\mathrm{Pt}$ to intermediate products, thus accelerating the oxygen reduction reaction.

In addition to excellent oxygen reduction electrocatalytic activity, they also exhibit good structural invariance. We use accelerated durability test (ADT) to evaluate their stability: 0.6 $-1.0 \mathrm{~V}$ under 10,000 potential cycles recorded at $100 \mathrm{mV} \mathrm{s}^{-1} \mathrm{in}$ $0.1 \mathrm{M} \mathrm{HClO}_{4}$. As shown in the diagram, attenuation is detected in the catalytic activity of Pt-Pd-Ni concave cubic attenuation,
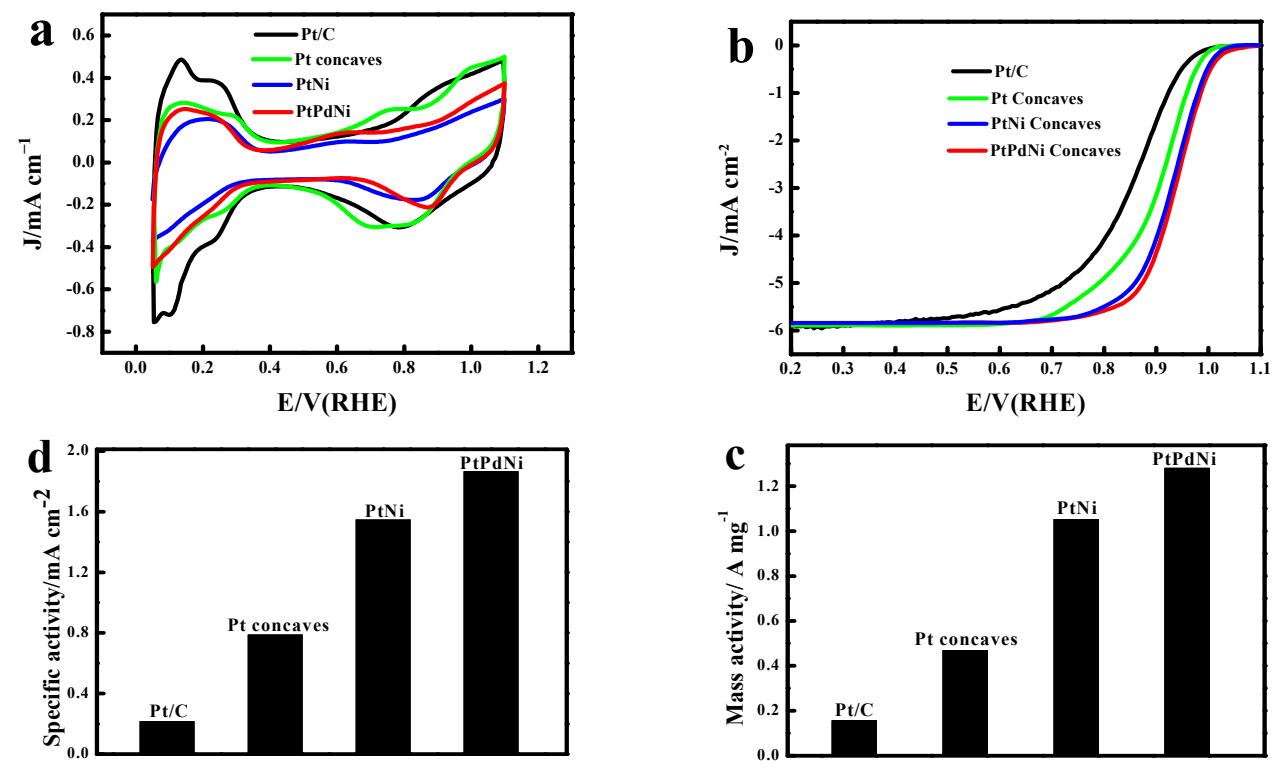

Fig. 4. (a) Cyclic voltammograms of Pt-Pd-Ni concaves, Pt-Ni concaves, Pt concaves and TKK-Pt/C catalyst recorded at $50 \mathrm{mV} \mathrm{s} \mathrm{s}^{-1}$; (b) ORR polarization curves of these catalysts recorded at $10 \mathrm{mV} \mathrm{s}^{-1}$; (c) Mass activities of different catalysts measured at $0.9 \mathrm{~V}$ versus RHE; (d) Specific activities of different catalysts measured at $0.9 \mathrm{~V}$ versus RHE. 

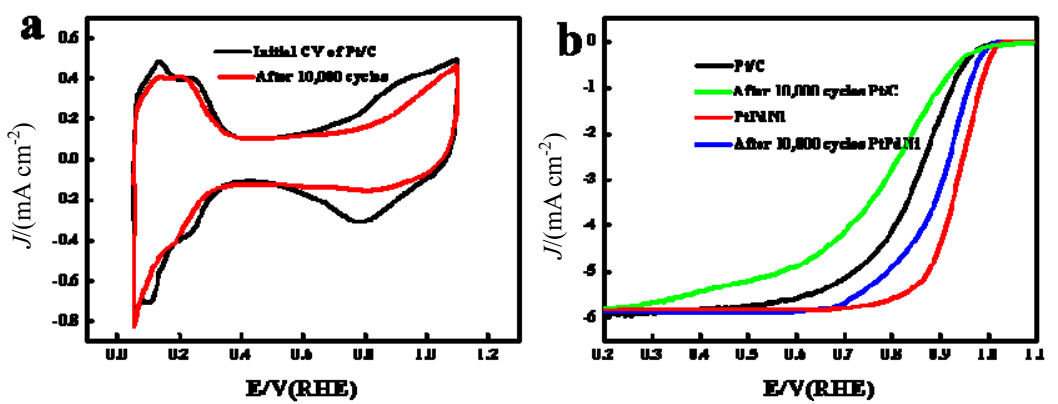

Fig. 5. (a) CV curves for the Pt/C before and after 10,000 CV potential cycles; (b) ORR polarization curves of the Pt-Pd-Ni concaves and TKK-Pt/C catalyst before and after 10,000 potential cycles.

their half-wave potential are positively shifted only $27 \mathrm{mV}$ after 10,000 potential cycles, and for the TKK-Pt/C, the half-wave potential are positively shifted more than $46 \mathrm{mV}$ after 10,000 potential cycles (Fig. 5(b)). The reason for this is the eroded $\mathrm{Ni}$ atoms within the structure, which is commonly seen in Pt-based alloy material. To solve the problem, we hamper the erosion of transitional metal elements by modifying atoms like $\mathrm{Au}, \mathrm{Rh}$ or Mo on the surface, which will further enhance the stability of ternary alloy [37-39].

\section{Conclusions}

In conclusion, PtPdNi concave cube structure is synthesized by one-pot method, and the ratio of DMF to oleamine is the main factor affecting the concave degree of PtPdNi. The morphology and composition of the PtPdNi concave cube are characterized in details. The formation mechanism of Pt-Pd-Ni concave cube is studied and it is considered that the ratio of CTAB, oleamine and DMF plays a key role in the synthesis of concave cube. Pt-Pd-Ni concave cubes have high electrocatalytic activity and stability for the cathodic oxygen reduction reaction of fuel cells due to the high concave degree, high space utilization and abundant high exponential surfaces of Pt-Pd-Ni concave cubes as well as synergistic effect between $\mathrm{Pt}$ and $\mathrm{Pd}$ and $\mathrm{Ni}$, and it provides more ideas and ways for further controlling of the synthesis of Pt-based nanocatalysts with different morphologies and structures for industrial applications in the future.

\section{Electronic supporting information}

Supporting information is available in the online version of this article.

\section{References}

[1] M. Z. Jacobson, W. G. Colella, D. M. Golden, Science, 2005, 308, 1901-1905.

[2] L. Zhang, K. Doyle-Davis, X. Sun, Energy Environ. Sci., 2019, 12, 492-517.

[3] X. Huang, Z. Zhao, L. Cao, Y. Chen, E. Zhu, Z. Lin, M. Li, A. Yan, A. Zettl, Y. M. Wang, X. Duan, T. Mueller, Y. Huang, Science, 2015, 348, 1230-1234.

[4] N. Tian, Z.-Y. Zhou, S.-G. Sun, Y. Ding, Z. L. Wang, Science, 2007, $316,732-735$.
[5] B. Lim, M. Jiang, P. H. Camargo, E. C. Cho, J. Tao, X. Lu, Y. Zhu, Y. Xia, Science, 2009, 324, 1302-1305.

[6] L. Zhang, L. T. Roling, X. Wang, M. Vara, M. Chi, J. Liu, S.-I. Choi, J. Park, J. A. Herron, Z. Xie, M. Mavrikakis, Y. Xia, Science, 2015, 349, 412-416.

[7] C. Chen, Y. Kang, Z. Huo, Z. Zhu, W. Huang, H. L. Xin, J. D. Snyder, D. Li, J. A. Herron, M. Mavrikakis, M. Chi, K. L. More, Y. Li, N. M. Markovic, G. A. Somorjai, P. Yang, V. R. Stamenkovic, Science, 2014, 343, 1339-1343.

[8] M. Li, Z. Zhao, T. Cheng, A. Fortunelli, C.-Y. Chen, R. Yu, Q. Zhang, L. Gu, B. V. Merinov, Z. Lin, E. Zhu, T. Yu, Q. Jia, J. Guo, L. Zhang, W. A. III Goddard, Y. Huang, X. Duan, Science, 2016, 354, 1414-1419.

[9] L. Bu, N. Zhang, S. Guo, X. Zhang, J. Li, J. Yao, T. Wu, G. Lu, J.-Y., Ma, D. Su, X. Huang, Science, 2016, 354, 1410-1414.

[10] Y. Wu, D. Wang, Z. Niu, P. Chen, G. Zhou, Y. Li, Angew. Chem. Int. Ed., 2012, 51, 12524-12528.

[11] B. Y. Xia, H. B. Wu, N. Li, Y. Yan, X. W. D. Lou, X. Wang, Angew. Chem. Int. Ed., 2015, 127, 3868-3872.

[12] F. Saleem, Z. Zhang, B. Xu, X. Xu, P. He, X. Wang, J. Am. Chem. Soc., 2013, 135, 18304-18307.

[13] X. Sun, K. Jiang, N. Zhang, S. Guo, X. Huang, ACS Nano, 2015, 9, 7634-7640.

[14] X. Yu, D. Wang, Q. Peng, Y. Li, Chem. Commun., 2011, 47, 8094-8096.

[15] Z. Quan, Y. Wang, J. Fang, Acc. Chem. Res., 2012, 46, 191-202.

[16] T. Yu, D. Y. Kim, H. Zhang, Y. Xia, Angew. Chem. Int. Ed., 2011, 50, 2773-2777.

[17] Z. Niu, D. Wang, R. Yu, Q. Peng, Y. Li, Chem. Sci., 2012, 3, 1925-1929.

[18] A. X. Yin, X. Q. Min, W. Zhu, W. C. Liu, Y. W. Zhang, C. H. Yan, Chem. Eur. J., 2012, 18, 777-782.

[19] X. Xu, X. Zhang, H. Sun, Y. Yang, X. Dai, J. Gao, X. Li, P. Zhang, H.-H. Wang, N.-F. Yu, S.-G. Sun, Angew. Chem., Int. Ed., 2014, 53, 12522-12527.

[20] J. P. Lai, Y. G. Chao, P. Zhou, Y. Yang, Y. L. Zhang, W. L. Yang, D. Wu, J. R. Feng, S. J. Guo, Electrochem. Energy Rev., 2018, 1, 531-547.

[21] Y. Yu, W. Yang, X. Sun, W. Zhu, X. Z. Li, D. J. Sellmyer, S. Sun, Nano Lett., 2014, 14, 2778-2782.

[22] M. Chen, J. Kim, J. P. Liu, H. Fan, S. Sun, J. Am. Chem. Soc., 2006, 128, 7132-7133.

[23] L. Zheng, X. Yu, M. Long, Q. Li, Chin. J. Catal., 2017, 38, 2076-2084.

[24] V. R. Stamenkovic, B. Fowler, B. S. Mun, G. Wang, P. N. Ross, C. A. Lucas, N. M. Marković, Science, 2007, 315, 493-497.

[25] J. Zhang, H. Yang, J. Fang, S. Zou, Nano Lett., 2010, 10, 638-644.

[26] Y. Wu, S. Cai, D. Wang, W. He, Y. Li, J. Am. Chem. Soc., 2012, 134, 8975-8981. 


\title{
Graphical Abstract
}

Chin. J. Catal., 2021, 42: 772-780 doi: 10.1016/S1872-2067(20)63703-2

\section{High-quality and deeply excavated PtPdNi nanocubes as efficient catalysts toward oxygen reduction reaction}

Yanjie Li, Rifeng Wu, Yang Liu, Ying Wen, Pei Kang Shen *

Guangxi University
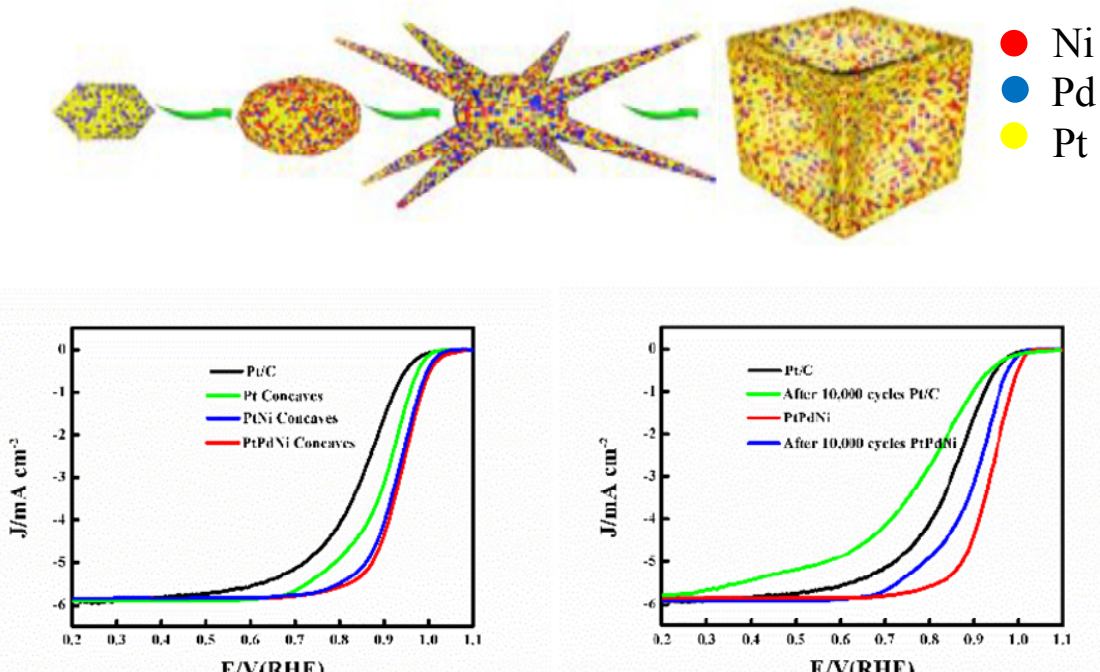

High-quality and deeply excavated PtPdNi nanocubes have been synthesized and show excellent catalytic activity for oxygen reduction reaction.

[27] C. Luan, Q. X. Zhou, Y. Wang, Y. Xiao, X. Dai, X. L. Huang, X. Zhang, Small, 2017, 13, 1702617.

[28] Q. Chen, Y. Yang, Z. Cao, Q. Kuang, G. Du, Y. Jiang, Z. Xie, L. Zheng, Angew. Chem. Int. Ed., 2016, 55, 9021-9025.

[29] H. Yang, J. Zhang, K. Sun, S. Zou, J. Fang, Angew. Chem. Int. Ed., 2010, 49, 6848-6851.

[30] F. Saleem, B. Ni, Y. Yong, L. Gu, X. Wang, Small, 2016, 12, 5261-5268.

[31] L. Gan, C. Cui, M. Heggen, F. Dionigi, S. Rudi, P. Strasser, Science, 2014, 346, 1502-1506.

[32] C. Cui, L. Gan, M. Heggen, S. Rudi, P. Strasser, Nat. Mater., 2013, 12,
765-771.

[33] M. K. Carpenter, T. E. Moylan, R. S. Kukreja, M. H. Atwan, M. M. Tessema, J. Am. Chem. Soc., 2012, 134, 8535-8542.

[34] S. Bai, C. Wang, W. Jiang, N. Du, J. Li, J. Du, R. Long, Z. Li, Y. Xiong, Nano Res., 2015, 8, 2789-2799.

[35] Y. Qi, T. Bian, S.-I. Choi, Y. Jiang, C. Jin, M. Fu, H. Zhang, D. Yang, Chem. Commun., 2014, 50, 560-562.

[36] V. Beermann, M. Gocyla, E. Willinger, S. Rudi, M. Heggen, R. E. Dunin-Borkowski, M.-G. Willinger, P. Strasser, Nano Lett., 2016, 16, 1719-1725.

[37] J. Zhang, K. Sasaki, E. Sutter, R. Adzic, Science, 2007, 315, 220-222.

\section{高质量和深度凹陷的PtPdNi纳米立方体作为高效氧还原反应的催化剂}

\author{
李彦杰，吴日枫，刘 洋，文 颖，沈培康*
}

广西大学可再生能源材料协同创新中心, 广西电化学能源材料重点实验室, 物理科学与工程中心, 广西南宁530004

摘要: 聚合物电解质燃料电池阴极上的氧还原反应需要使用铂基催化剂, 铂是地球上的贵金属之一. 采用将不同的金属优 化到核心中等多种策略可提高铂基催化剂的活性, 从而降低铂的负载量. 通过致力于高催化活性 $\mathrm{Pt}_{2.7} \mathrm{Pd}_{0.3} \mathrm{Ni}$ 凹面立方结构 与高指数晶面的复合, 表明凹面结构可以提供更多的活性位和高水平的催化活性, 如果与其他金属复合, 可以降低铂的比 例, 提高其质量活性. 本文采用一锅法合成了PtPdNi凹立方体结构, 并发现DMF和油胺的比例是影响PtPdNi凹陷程度的主 要因素. 通过对PtPdNi凹立方体的形态和组成进行详细表征, 研究了PtPdNi凹立方体的形成机理, 认为十六烷基三甲基澳 化铵、油酸胺和二甲基甲酰胺的比例在 $\mathrm{PtPdNi}$ 凹立方体的合成中起着关键作用. 本文还对 $\mathrm{Pt}_{2.7} \mathrm{Pd}_{0.3} \mathrm{Ni}$ 凹立方结构形成的理 论和条件进行了探讨, 并通过改变反应条件, 考察了其所表现出的差异. 电化学测试的氧还原性能结果表明, 凹面立方体 形状的PtPdNi催化剂在 $0.9 \mathrm{~V}$ 下的质量活性为 $1.28 \mathrm{mg}_{\mathrm{Pt}}{ }^{-1}$, 最高质量活性和比活性分别是市售铂炭的 8.20 倍和 8.68 倍. 铂钯 
镍三元纳米笼具有优异的结构稳定性, 经稳定性测试, 纳米结构没有明显的变化和性能退化. PtPdNi凹立方体对阴极具有 很高的电催化活性和稳定性, 燃料电池的氧还原反应由于高凹度、高空间利用率和PtPdNi凹立方体丰富的高指数表面以及 $\mathrm{PtPdNi}$ 之间的协同效应, 为进一步控制铂基纳米催化剂的合成提供更多的思路和方法及未来工业应用的不同形态和结构. 关键词: 氧还原反应; 聚合物电解质燃料电池; 凹面立方结构; 电化学催化剂

收稿日期: 2020-04-18. 接受日期: 2020-06-23. 上网日期: 2020-09-22.

*通讯联系人. 电话: (0771)3237990; 电子信箱: pkshen@gxu.edu.cn

基金来源：国家自然科学基金-福建联合基金(U1705252); 广西重点基金(AA17204083，AB16380030); 广东自然科学基金 (2015A030312007).

本文的电子版全文由Elsevier出版社在ScienceDirect上出版(http://www.sciencedirect.com/science/journal/18722067). 